\title{
AMENDMENTS
}

\section{Publisher Correction: Process-based framework for precise neuromodulation}

Nitzan Lubianiker, Noam Goldway (D), Tom Fruchtman-Steinbok, Christian Paret (D), Jacob N Keynan, Neomi Singer, Avihay Cohen, Kathrin Cohen Kadosh, David E J Linden and Talma Hendler (iD

Correction to: Nature Human Behaviour https://doi.org/10.1038/s41562-019-0573-y, published online 15 April 2019.

In the version of this article initially published, in Fig. $1 \mathrm{~b}$ the green smiley faces were in the wrong order: the smiling face should have been on the left and the frowning face should have been on the right. The error has been corrected in the HTML and PDF versions of the article.

In addition, the Editorial Summary did not appear on the website:

"Neurofeedback training is considered a promising tool in psychiatric intervention. To enable neurofeedback to fulfil its promise, Lubianiker et al introduce a process-based neurofeedback framework to guide future research and interventions."
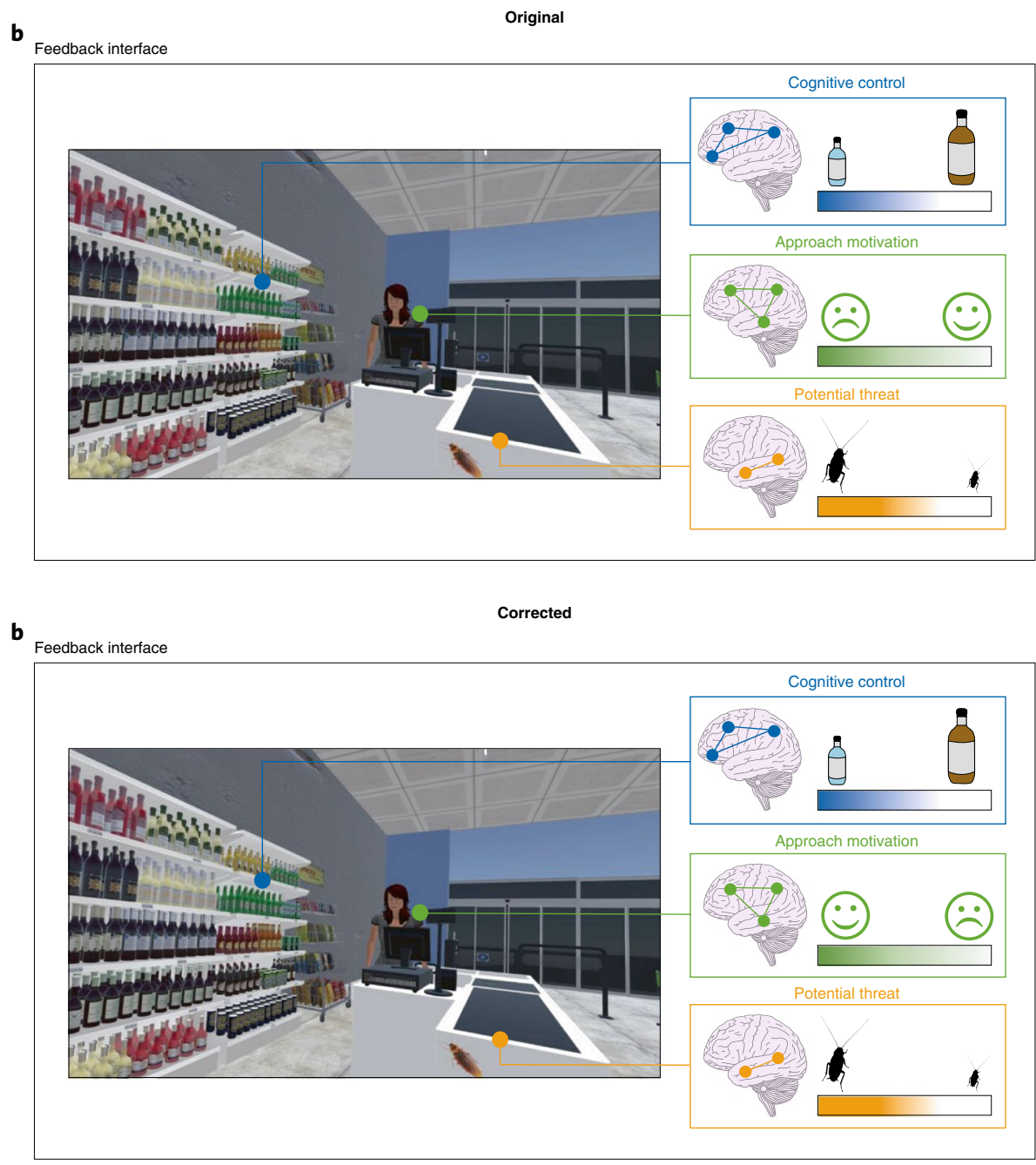

Fig. 1 | Orginal and Corrected. 